\title{
Effectiveness Analysis on Human-Machine Information Interaction of Intelligent Highway
}

\author{
Yicheng Zhou, ${ }_{1}^{1}$ Tuo Sun $\mathbb{D}^{\mathrm{D}},{ }^{2}$ Shunzhi Wen, ${ }^{1}$ Hao Zhong $\mathbb{D}^{2},{ }^{2}$ Youkai Cui, ${ }^{1}$ Jiemin Xie, ${ }^{3}$ \\ Wei Wu, ${ }^{1}$ and Wanjing $M a$ iD $^{2}$ \\ ${ }^{1}$ Zhejiang Institute of Communications Co., Ltd., Zhejiang 310030, China \\ ${ }^{2}$ Key Laboratory of Road and Traffic Engineering of the Ministry of Education, Tongji University, Shanghai 201804, China \\ ${ }^{3}$ School of Intelligent Systems Engineering, Sun Yat-Sen University, Guangzhou 510275, China
}

Correspondence should be addressed to Hao Zhong; 2110191@tongji.edu.cn

Received 7 November 2021; Accepted 30 December 2021; Published 11 January 2022

Academic Editor: Muqing Du

Copyright $(92022$ Yicheng Zhou et al. This is an open access article distributed under the Creative Commons Attribution License, which permits unrestricted use, distribution, and reproduction in any medium, provided the original work is properly cited.

Different human-machine collaboration modes and driving simulation tests with the orthogonal method considered are designed for a series of typical intelligent highway landscapes. The feedback of drivers under different interaction modes is evaluated through NASA-LTX questionnaire, driving simulator, eye tracker, and electroencephalograph (EEG). This optimal interaction mode (including voice form, broadcasting timing, and frequency) of each driving assistance scene in CVI (Cooperative Vehicle Infrastructure) environment under the conditions of high and low traffic is determined from subjective and objective perspectives. In accordance with feedback of these subjects on each set scene, the voice information structure of each assistance mode plays the most important role on drivers followed by the broadcasting timing and frequency. These broadcasts which provide good effects include scenarios such as various assistance scenes at curves and an early warning timing at a long-distance trip as well as a high early warning frequency; in addition, as for an exit-tip assistance scenario, a voice mode assistance is preferred; and for various speed assistance scenes, the beep mode is better. Furthermore, it is found that, at a higher traffic level but a short-distance trip, an early warning timing is favored generally for various scenes while under a low traffic level, a long-distance early warning timing is better.

\section{Introduction and Background}

Compared with the traditional traffic environment, while drivers are under the cooperative vehicle infrastructure environment, they can obtain more accurate information regarding the traffic environment and surrounding vehicles at any time. However, the diversity and universality of information collected and presented by the vehicle cell also bring some challenges to the driver's decision-making. These unreasonable collaborative information settings may diminish the safety and efficiency of vehicle driving.

In terms of the content of early warning information, Creaser et al. find that the human-machine interaction system in the cooperative vehicle infrastructure environment can effectively improve driving safety, but too much information presented may distract the driver's attention [1].
In terms of the form of early warning information, Emily et al. conduct a comparative study on the voice parameters of early warning and find that a higher voice frequency and density can improve the vehicle braking efficiency of drivers. However, growing the duration of early warning voice will not significantly improve the assistance effect of early warning [2]. Based on the scene of sudden braking of the vehicle in front, Chin et al. compare the response to the two early warning voice modes of monosyllabic abstract sound and voice. The results show that the driver's response time is shorter and the standard deviation of vehicle trajectory is smaller under the early warning model of the monosyllabic abstract sound [3]. The paper of Susan et al. on forwarding collision warning of vehicle shows that, compared with the multichannel image and voice warning mode, the driver under the condition of only image warning requires a greater 
safety distance for forwarding collision warning [4]. Doshi et al. compare the four conditions of no early warning, image warning, digital warning, and image-digital warning and find that the driving speed has been obviously controlled under the condition of early warning display. In addition, they propose that the basic principle of early warning display of human-machine interaction is to provide accurate information of deceleration to quickly attract the driver's attention and ensure that their attention is inside the road range [5]. In terms of the broadcasting timing of early warning information, Takashi et al. find that the time to collision (TTC) longer than $10 \mathrm{~s}$ is relatively safe, and early warning when TTC is greater than this critical value will interfere with the driver's driving [6]. Yan et al. find that the lead time of early warning of $5.5 \mathrm{~s}$ can achieve a good early warning effect for the impending dangerous situation while the drivers should be given at least 2.5 -second reaction time for the braking reaction to ensure safety [7]. In terms of the broadcasting frequency of early warning information, Hans et al. compare the one-level voice warning with the two-level voice warning. If the deviation trend of the vehicle is corrected within a one-level voice warning, the level-1 alarm will be released immediately. If not, the level- 2 alarm will be commenced. Finally, it is found that since a level-1 alarm may occur when an early warning is not needed, the driver will ignore the level- 1 alarm after adapting to it and respond only when a level- 2 alarm occurs, resulting in the loss of significance of level-1 alarm.

To sum up, under the cooperative vehicle infrastructure scene, different information interaction settings of vehicle driving assistance mean to have different effects on driving performance along with both physiological and psychological state. However, there is still a lack of comprehensive evaluation on the human-machine interactive information content including broadcasting form, timing, and frequency. In consideration of the above problems, a paper is carried out to determine the optimal information content, broadcasting form, timing, and frequency in various traffic scenes, which is of great significance for driving safety and efficiency.

\section{Experiments Design}

The paper has carried out the experimental design from five aspects, i.e., participants, apparatus, scenario, interactive information, and test process.

2.1. Participants. Criteria of a proper subject are as follows: (a) age between 22 and 60; (b) holding a valid Chinese driving license; (c) no motion sickness or epilepsy. 136 qualified candidates were confirmed after issuing the recruitment announcement. According to the proportion of gender, age, and driving experience of drivers in China (namely, male: female $=7: 3$, youth: middle-aged and elderly $=1: 1$, beginner: experienced driver $=1: 1$ ), 40 people were randomly selected by graded sampling. All participants were trained in the driving simulator in order to avoid simulator sickness and be familiar with the operation of the driving simulator, which contained three parts: understanding of interactive information; acceleration, deceleration, and stop training; collision-free driving. Participants who showed simulator sickness had to be excluded from the experiment. Simulator sickness is identified mainly by selfreport. Finally, 38 participants passed the training and completed the experiment and the valid sample data are collected. The specific statistical information of subjects is shown in Table 1.

2.2. Apparatus. As shown in Figure 1, tests of road safety and driving behavior were carried out on a one-man fixed base simulator equipped with the steering wheel, clutch, accelerator, and brake pedal. The driving simulator provided $180^{\circ}$ front view images with $2560 \times 1600$ resolution. This simulator was controlled by SCANeR Studio [8], and the data that can be collected refer to driving behaviors such as steering wheel angle as well as vehicle conditions such as vehicle position, speed, acceleration, and yaw angle. The eye movement state of the subjects when driving is monitored by Tobii Glass2 spectacle type eye-tracking equipment [9], which can obtain fixation, saccade, and pupil data. To record the brain state of the subjects, Neurosky MindWave Mobile EEG headset [10] was used to quantitatively process electroencephalogram signals, which can collect multiband electroencephalogram data.

2.3. Scenario Design. A two-way eight-lane highway section was constructed in the driving simulator, including a long downhill, an exit ramp, and a service area exit. The width of each lane was $3.75 \mathrm{~m}$ and the total length of lanes was no more than $10 \mathrm{~km}$. The setting of traffic signs and markings in the test scene met the national standard (GB5768-2009). In addition, high and low traffic flows were set, respectively, namely, $2000 \mathrm{veh} / \mathrm{h} / \mathrm{ln}$ and $800 \mathrm{veh} / \mathrm{h} / \mathrm{ln}$. Eight scenes were considered in the test, including speed limit change, overspeed, sharp turn/continuous turn, long and steep downhill, exit ahead, service area ahead, traffic congestion ahead, and static/slow vehicle ahead. In addition, a difference of effects of some scenes on straight and curve sections was considered as well. The scenes were connected in series in the order as shown in Figure 2. Numbers in the figure correspond to the scenes as follows:

(1) Static/slow vehicle warning ahead at the straight line

(2) Speed limit change at the straight line

(3) Overspeed at the straight line

(4) Sharp turn/continuous turn

(5) Speed limit change at the curve

(6) Static/slow vehicle ahead at the curve

(7) Service area ahead

(8) Long and steep downhill

(9) Traffic congestion ahead

(10) Exit ahead

(11) Overspeed at the curve 
TABLE 1: Statistical information of subjects.

\begin{tabular}{lccccccccc}
\hline Gender & & \multicolumn{2}{c}{ Age } & \multicolumn{2}{c}{ Driving years } & Professional \\
Average & $\begin{array}{c}\text { Stand } \\
\text { value }\end{array}$ & $\begin{array}{c}\text { Average } \\
\text { deviation }\end{array}$ & $\begin{array}{c}\text { Stand } \\
\text { value }\end{array}$ & $\begin{array}{c}\text { Nonprofessional } \\
\text { devition }\end{array}$ & $\begin{array}{c}\text { Know driving } \\
\text { driver }\end{array}$ & $\begin{array}{c}\text { Do not know } \\
\text { driving } \\
\text { assistance }\end{array}$ \\
\hline Male & 26 & 39.36 & 13.14 & 8.8 & 5.64 & 16 & 10 & 16 & 10 \\
Female & 12 & 31.25 & 13.38 & 6.8 & 6.02 & 6 & 6 & 9 & 3 \\
Total & 38 & 35.11 & 13.34 & 7.9 & 5.98 & 22 & 16 & 25 & 13 \\
\hline
\end{tabular}

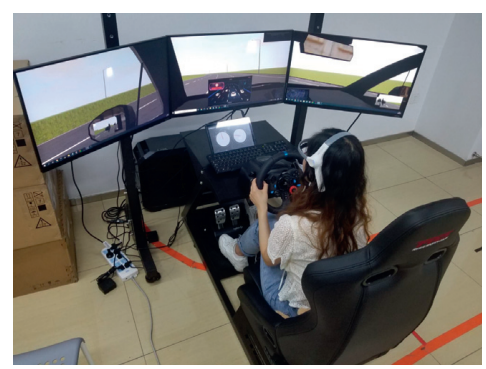

(a)

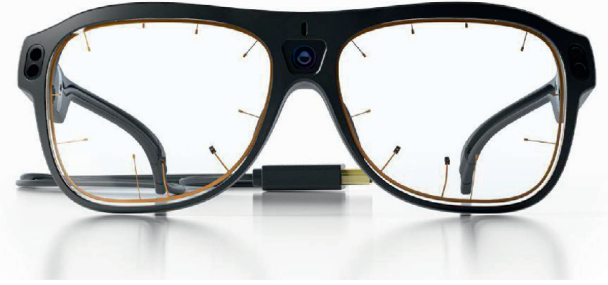

(b)

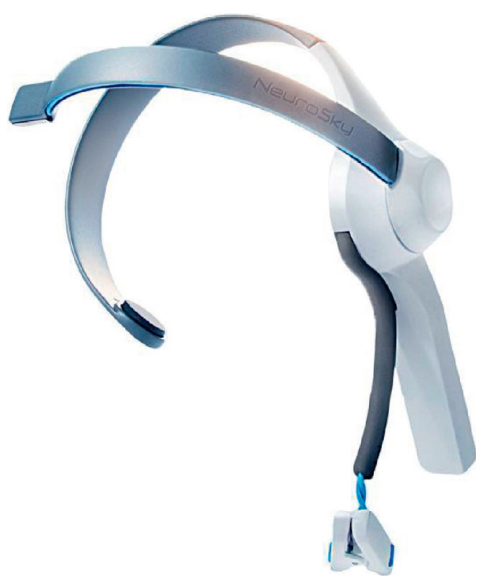

(c)

FIgUre 1: Test instruments. (a) Driving simulator. (b) Eye tracker. (c) EEG.

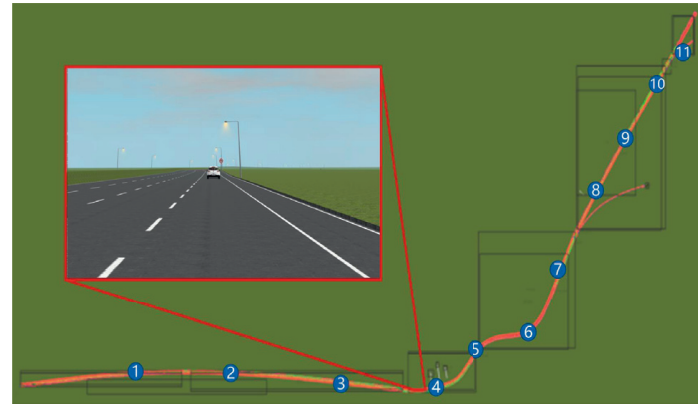

FIgURE 2: Test scenario.

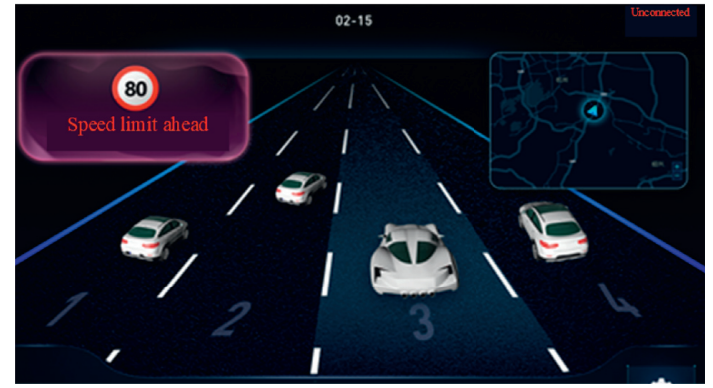

Figure 3: Interface example.
2.4. Design of Interactive Information. The image and voice multichannel assistance mode was adopted, and the effect of early warning timing and frequency were considered as well. For the early warning images, referring to previous research and market research and based on the iterative man-machine interface design method (understanding the application environment and the user's needs, designing the scheme according to the needs, and evaluating four phases according to the needs) and the basic layout principles of zoning design and information reclassification, the information interaction interface forms of 8 scenes were designed. The early warning information in the interface changes with the scene category and trigger timing. Figure 3 illustrates an example.

Two levels of short-distance and long-distance early warning before the dangerous area were set for the trigger timing of early warning information; as for the trigging frequency of early warning information, two levels of low frequency (one time) and high frequency (three times) early warning were established; and for the voice form, two levels of beep and voice broadcast were set. The content of voice broadcast under various combinations of trigger timing and trigger frequency of early warning information was as shown in Table 2, and the pacing was about 5 words per second.

2.5. Test Process. The test process was divided into four stages: preliminary questionnaire survey, driving simulation training, formal test, and subjective evaluation. During driving, drivers wearing an eye tracker and EEG to record all data were asked to drive as usual. If the driver understood the design of the driving assistance system, he/she would follow the tips to drive more carefully. The test took an average time of one hour for each driver, including a test time of 50 minutes and a preparation time of 10 minutes. 
TABLE 2: Content of voice broadcast under various combinations of trigger timing and trigger frequency.

\begin{tabular}{|c|c|c|c|c|}
\hline Scene & $\begin{array}{l}\text { High frequency/short } \\
\text { distance }\end{array}$ & High frequency/long distance & $\begin{array}{l}\text { Low frequency/short } \\
\text { distance }\end{array}$ & Low frequency/long distance \\
\hline \multirow{3}{*}{$\begin{array}{l}\text { Speed limit } \\
\text { change }\end{array}$} & $\begin{array}{l}\text { The speed limit } 200 \mathrm{~m} \\
\text { ahead is } 80 / 60 \mathrm{~km} / \mathrm{h}\end{array}$ & $\begin{array}{l}\text { The speed limit } 500 \mathrm{~m} \text { ahead is } 80 / \\
\qquad 60 \mathrm{~km} / \mathrm{h}\end{array}$ & $\begin{array}{l}\text { The speed limit } 200 \mathrm{~m} \\
\text { ahead is } 80 / 60 \mathrm{~km} / \mathrm{h}\end{array}$ & $\begin{array}{l}\text { The speed limit } 500 \mathrm{~m} \text { ahead is } \\
110 / 80 / 60 \mathrm{~km} / \mathrm{h}\end{array}$ \\
\hline & The speed limit is $80 /$ & $\begin{array}{l}\text { The speed limit } 200 \mathrm{~m} \text { ahead is } 80 / \\
\qquad 60 \mathrm{~km} / \mathrm{h}\end{array}$ & & \\
\hline & & The speed limit is $110 / 80 / 60 \mathrm{~km} / \mathrm{h}$ & & \\
\hline \multirow{2}{*}{ Overspeed } & $\begin{array}{l}\text { You are speeding. The } \\
\text { speed limit is } 80 / 60 \mathrm{~km} / \\
\text { h. Please slow down. }\end{array}$ & $\begin{array}{l}\text { Speed camera } 500 \mathrm{~m} \text { ahead. The } \\
\text { speed limit is } 80 / 60 \mathrm{~km} / \mathrm{h} \text {. Please } \\
\text { slow down. }\end{array}$ & $\begin{array}{l}\text { You are speeding. The } \\
\text { speed limit is } 80 / \\
60 \mathrm{~km} / \mathrm{h} \text {. Please slow } \\
\text { down. }\end{array}$ & $\begin{array}{c}\text { Speed camera } 500 \mathrm{~m} \text { ahead. The } \\
\text { speed limit is } 80 / 60 \mathrm{~km} / \mathrm{h} \text {. Please } \\
\text { slow down. }\end{array}$ \\
\hline & $\begin{array}{l}\text { You are passing through } \\
\text { with an overspeed of } X\end{array}$ & $\begin{array}{l}\text { You are speeding. The speed limit } \\
\text { is } 80 / 60 \mathrm{~km} / \mathrm{h} \text {. Please slow down. } \\
\text { You are passing through with an } \\
\text { overspeed of } X\end{array}$ & & \\
\hline \multirow{2}{*}{$\begin{array}{l}\text { Sharp turn/ } \\
\text { continuous } \\
\text { turn }\end{array}$} & $\begin{array}{l}\text { Sharp turn/continuous } \\
\text { turn } 200 \mathrm{~m} \text { ahead. Please } \\
\text { slow down. }\end{array}$ & $\begin{array}{l}\text { Continuous turn } 500 \mathrm{~m} \text { ahead. } \\
\text { Please slow down. }\end{array}$ & $\begin{array}{l}\text { Sharp turn/continuous } \\
\text { turn } 200 \mathrm{~m} \text { ahead. } \\
\text { Please slow down. }\end{array}$ & $\begin{array}{l}\text { Continuous turn } 500 \mathrm{~m} \text { ahead. } \\
\text { Please slow down. }\end{array}$ \\
\hline & $\begin{array}{l}\text { Sharp turn/continuous } \\
\text { turn }\end{array}$ & $\begin{array}{l}\text { Continuous turn } 200 \mathrm{~m} \text { ahead. } \\
\text { Please slow down. } \\
\text { Continuous turn }\end{array}$ & & \\
\hline \multirow{2}{*}{$\begin{array}{l}\text { Long and steep } \\
\text { downhill }\end{array}$} & $\begin{array}{l}\text { Long and steep downhill } \\
500 \mathrm{~m} \text { ahead. Please slow } \\
\text { down }\end{array}$ & $\begin{array}{l}\text { Long and steep downhill } 1000 \mathrm{~m} \\
\text { ahead. Please slow down. }\end{array}$ & $\begin{array}{l}\text { Long and steep } \\
\text { downhill } 500 \mathrm{~m} \text { ahead. } \\
\text { Please slow down. }\end{array}$ & $\begin{array}{l}\text { Long and steep downhill } 1000 \mathrm{~m} \\
\text { ahead. Please slow down. }\end{array}$ \\
\hline & $\begin{array}{l}\text { End of long and steep } \\
\text { downhill }\end{array}$ & $\begin{array}{l}\text { Long and steep downhill } 500 \mathrm{~m} \\
\text { ahead. Please slow down. } \\
\text { End of long and steep downhill }\end{array}$ & & \\
\hline \multirow[t]{2}{*}{ Exit ahead } & $\begin{array}{l}\text { You will get off the } \\
\text { highway } 500 \mathrm{~m} \text { ahead. } \\
\text { Please drive in the } \\
\text { rightmost lane. }\end{array}$ & $\begin{array}{l}\text { Toll station } 1000 \mathrm{~m} \text { ahead. If you } \\
\text { will get off the highway via this } \\
\text { exit, please pay attention to rear } \\
\text { vehicles and change lanes in } \\
\text { advance. }\end{array}$ & $\begin{array}{l}\text { You will get off the } \\
\text { highway } 500 \mathrm{~m} \text { ahead. } \\
\text { Please drive in the } \\
\text { rightmost lane. }\end{array}$ & $\begin{array}{l}\text { Toll station } 1000 \mathrm{~m} \text { ahead. If you } \\
\text { will get off the highway via this } \\
\text { exit, please pay attention to rear } \\
\text { vehicles and change lanes in } \\
\text { advance. }\end{array}$ \\
\hline & $\begin{array}{l}\text { Please get off the } \\
\text { highway via the exit with } \\
\text { a speed limit of } 40 \mathrm{~km} / \mathrm{h}\end{array}$ & $\begin{array}{l}\text { You will get off the highway } 500 \mathrm{~m} \\
\text { ahead. Please drive in the } \\
\text { rightmost lane. }\end{array}$ & & \\
\hline \multirow{3}{*}{$\begin{array}{l}\text { Service area } \\
\text { ahead }\end{array}$} & & $\begin{array}{l}\text { Please get off the highway via the } \\
\text { exit with a speed limit of } 40 \mathrm{~km} / \mathrm{h}\end{array}$ & & \\
\hline & Service area $500 \mathrm{~m}$ ahead & Service area $1000 \mathrm{~m}$ ahead & $\begin{array}{c}\text { Service area } 500 \mathrm{~m} \\
\text { ahead }\end{array}$ & Service area $1000 \mathrm{~m}$ ahead \\
\hline & Arrival of service area & $\begin{array}{l}\text { Service area } 500 \mathrm{~m} \text { ahead } \\
\text { Arrival of service area }\end{array}$ & & \\
\hline \multirow{3}{*}{$\begin{array}{l}\text { Traffic } \\
\text { congestion } \\
\text { ahead }\end{array}$} & $\begin{array}{l}\text { Traffic congestion } 500 \mathrm{~m} \\
\text { ahead. Please slow } \\
\text { down. } \\
\text { Enter the congested }\end{array}$ & $\begin{array}{l}\text { Traffic congestion } 1000 \mathrm{~m} \text { ahead. } \\
\text { The estimated passing time is } X \\
\text { minutes. Please slow down. }\end{array}$ & $\begin{array}{l}\text { Traffic congestion } \\
500 \mathrm{~m} \text { ahead. Please } \\
\text { slow down. }\end{array}$ & $\begin{array}{l}\text { Traffic congestion } 1000 \mathrm{~m} \text { ahead. } \\
\text { The estimated passing time is } X \\
\text { minutes. Please slow down. }\end{array}$ \\
\hline & $\begin{array}{l}\text { Enter the congested } \\
\text { section. The estimated } \\
\text { passing time is } X \\
\text { minutes. }\end{array}$ & $\begin{array}{l}\text { Traffic congestion } 500 \mathrm{~m} \text { ahead. } \\
\text { Please slow down. }\end{array}$ & & \\
\hline & & $\begin{array}{c}\text { Enter the congested section. The } \\
\text { estimated passing time is } X \\
\text { minutes. }\end{array}$ & & \\
\hline $\begin{array}{l}\text { Static/slow } \\
\text { vehicle warning } \\
\text { ahead }\end{array}$ & $\begin{array}{l}\text { Slow vehicle } 110 \mathrm{~m} \\
\text { ahead. Please drive } \\
\text { carefully. } \\
\text { Approaching slow } \\
\text { vehicle }\end{array}$ & $\begin{array}{c}\text { Slow vehicle } 250 \mathrm{~m} \text { ahead. Please } \\
\text { keep a safe distance or change the } \\
\text { lane in advance. } \\
\text { Slow vehicle } 110 \mathrm{~m} \text { ahead. Please } \\
\text { drive carefully. } \\
\text { Approaching slow vehicle }\end{array}$ & $\begin{array}{l}\text { Slow vehicle } 110 \mathrm{~m} \\
\text { ahead. Please drive } \\
\text { carefully. }\end{array}$ & $\begin{array}{l}\text { Slow vehicle } 250 \mathrm{~m} \text { ahead. Please } \\
\text { keep a safe distance or change the } \\
\text { lane in advance. }\end{array}$ \\
\hline
\end{tabular}


Finally, all drivers signed the informed consent form and obtained corresponding allowances.

2.5.1. Preliminary Questionnaire Survey. Each driver was asked to complete a questionnaire about his/her age, gender, education, driving years, and driving frequency. Before driving training, drivers were given a brief description of the simulation test and assistance mode.

2.5.2. Driving Simulation Training. During the training stage, some basic information about the use of the simulator was given to drivers and they were allowed to conduct a 5minute driving exercise to familiarize themselves with the simulator. During that training, all data of each driver during normal driving were recorded. And after this training, each participant was questioned by the organizer to leave the simulator cabin for 5 minutes to recover the physical and mental status at the beginning of the test.

2.5.3. Formal Test. As shown in Table 3, there were 8 tests conducted at the specified traffic level for each participant. These 8 tests were all designed according to the original orthogonal test form and all forms would be reset after each time of test. To eliminate the sequence effect in the tests and any sequence deviation related to parameter changes, the 8 tests for each participant were randomly arranged. On the whole, 38 participants participated in each experiment parameter setting.

2.5.4. Subjective Evaluation. After each test, ask the subject to complete the subjective evaluation questionnaire and generally use NASA-LTX questionnaire [11] to evaluate the mental load and physical load during driving. Each subject needs to complete the questionnaire 8 times in total. In addition, a comprehensive evaluation questionnaire of which the number of questions is reduced by the maximum difference measurement method was provided. The questionnaire was used to obtain the subjective weight of each subject for the important parameters in NASA-TLX.

\section{Comprehensive Analysis and Evaluation}

As for the evaluation of information interaction form, a multichannel evaluation method combining subjective and objective evaluation was adopted. NASA-LTX questionnaire was used for the individual evaluation to explore the driver's psychological load on the information. On the one hand, the eye tracker, EEG, and driving simulator to obtain the driver's eye movement characteristics, mental load, and driving performance under various information interaction conditions were used, respectively, for the objective evaluation. Then entropy-TOPSIS model [12] was applied for a comprehensive evaluation to determine the optimal driving assistance mode under each scenario.

\subsection{Subjective Evaluation by NASA-LTX Questionnaire.} For the subjective evaluation, according to the feedback of drivers on each scene and based on the mental load, physical load, and sense of time urgency, use the occurrence frequency of each affecting factor obtained by the maximum difference measurement method, to determine the weight of importance (sum of 1) of each subject for each affecting factor, and then the driver's mental load was obtained at various information interaction modes in cooperative vehicle infrastructure environment and at various traffic levels.

The average value of a mental load of subjects at various information interaction modes in a cooperative vehicle infrastructure environment and at high and low traffic levels was as shown in Figure 4. The results of the above orthogonal test are further subject to range analysis and it found that "short distance/high frequency/voice" applies the minimum subjective mental load to the driver. At the low traffic level, the voice information form had the greatest impact, followed by information trigger timing and information trigger frequency. Through comprehensive analysis, it was found that "long-distance/low frequency/voice" applied the minimum subjective mental load to the driver.

\subsection{Objective Evaluation by Entropy-TOPSIS Model}

3.2.1. Extraction of Evaluation Indexes. Key eye movement indexes during driving were extracted from the data of the eye tracker. It is necessary to preprocess the eye movement feature data to eliminate abnormal data such as missing values and divide the time period (namely, time of interest (TOI)) when the scene occurs, marking the spatial area (namely, area of interest (AOI)) where the early warning interface occurs in each scene. The main indexes to be collected included fixation time within AOI, saccade time within AOI, and pupil area. EEG was used to evaluate the mental load during driving. After collecting various brain waves, the wavelet threshold denoising algorithm was practical to remove the noise of brain wave, divide the preprocessed EEG data into fragments according to the sequence of scenes, implement Fast Fourier Transform for the EEG data at each stage, and extract the power spectral density of different brain waves in the fragment. On the basis of solving the power spectrum, the indexes were established such as the average power ratio of rhythm wave $\theta / \alpha$ and $\theta / \beta$. The driver's operation behavior refers to the control of the vehicle control device, and the control rationality directly affected the vehicle running effect. In terms of efficiency, indexes were found such as running time and average speed for evaluation. In terms of safety, the maximum deceleration amount, deceleration rate, mean acceleration, speed standard deviation, and lane changing times were considered as well. The details could be seen in Table 4 .

\subsubsection{Establishment and Standardization of Index Matrix.} There are $f$ types of traffic levels and $s$ types of cooperative vehicle infrastructure scenes at each traffic level. For each cooperative vehicle infrastructure scene, there are $n$ driving assistance schemes to be evaluated and there are $m$ evaluation indexes in each evaluation scheme. The initial index matrix $X_{i j}^{r q}(r=1,2, \ldots, f ; q=1,2, \ldots, n ; j=1,2, \ldots, m)$ in certain cooperative vehicle infrastructure scene at certain 
TABLe 3: Arrangement of test for each subject.

\begin{tabular}{lcccc}
\hline S/N & Traffic condition & Information trigger timing & Information trigger frequency & Voice information form \\
\hline 1 & High traffic & Short distance & Low frequency & Beep \\
2 & Low traffic & Short distance & Low frequency & Beep \\
3 & High traffic & Short distance & High frequency & Voice broadcast \\
4 & Low traffic & Short distance & High frequency & Voice broadcast \\
5 & High traffic & Long distance & Low frequency & Voice broadcast \\
6 & Low traffic & Long distance & Low frequency & Voice broadcast \\
7 & High traffic & Long distance & High frequency & Beep \\
8 & Low traffic & Long distance & High frequency & Beep \\
\hline
\end{tabular}

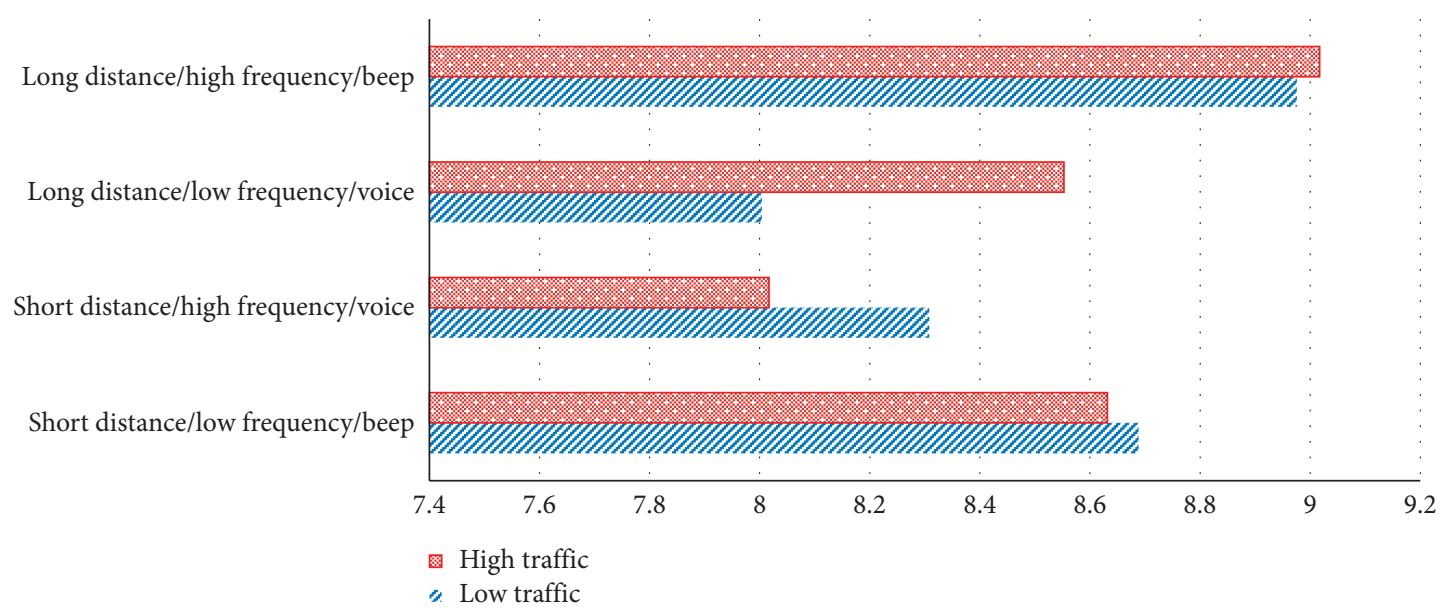

Figure 4: Subjective mental load at high and low traffic levels.

traffic level can be obtained. High traffic level (No. 1) and low traffic level (No. 2) are used in the test. There are 11 cooperative vehicle infrastructure scenes at each traffic level, 4 schemes to be evaluated in each scene, and 13 indexes in each scheme.

After the initial index matrix is obtained, the original value is used for each positive index while the negative index is subject to orthogonalization: $X_{i j}^{r q \#}=\max _{1 \leq i \leq n}\left\{X_{i j}^{r q}\right\}-x_{i j}^{r q}$ which will not change the original distribution law of negative indexes. Nondimensionalize the index value to eliminate the dimensional effect. The specific way is $X_{i j}^{r q *}=x_{i j}^{r q \#} / \bar{x}_{j}^{r q \#}$. For example, for the long and steep downhill scene at high traffic level, it finds that $X_{i j}^{18 *}(i=$ $1,2,3,4 ; j=1,2, \ldots, 13)$ is as follows:

$$
\left[\begin{array}{lllllllllllll}
1.448 & 2.086 & 0.000 & 0.601 & 1.159 & 0.870 & 2.330 & 1.028 & 2.685 & 1.464 & 1.984 & 2.373 & 1.904 \\
0.000 & 0.269 & 2.087 & 1.506 & 2.020 & 1.681 & 0.187 & 0.980 & 0.392 & 1.368 & 0.000 & 0.468 & 1.714 \\
1.307 & 0.000 & 0.654 & 1.892 & 0.820 & 1.449 & 1.482 & 1.028 & 0.000 & 1.167 & 1.104 & 1.588 & 0.381 \\
1.245 & 1.645 & 1.258 & 0.000 & 0.000 & 0.000 & 0.000 & 0.964 & 0.922 & 0.000 & 0.911 & 0.000 & 0.000
\end{array}\right] .
$$

3.2.3. Determination of Objective Weight. Conduct nonnegative translation for the initial index matrix and use the entropy method to calculate the objective weight of the standardized index. The greater the dispersion degree of the index is, the greater the entropy value will be, indicating that the index has a greater effect (i.e., weight) on the comprehensive evaluation. The entropy value is calculated as per the formula: $\quad E_{j}^{r q}=-\ln (n)^{-1} \sum_{i=1}^{n} p_{i j}^{r q} \ln \left(p_{i j}^{r q}\right), \quad$ where $p_{i j}^{r q *}=x_{i j}^{r q *} / \sum_{i=1}^{n} x_{i j}^{r q *} ; \quad$ if $\quad p_{i j}^{r q}=0, \quad$ then $\lim _{p_{i j}^{r q} \longrightarrow 0} p_{i j}^{r q} \ln \left(p_{i j}^{r q}\right)=0$. Accordingly, the weight of each index is calculated with the entropy value: $W_{j}^{r q}=\left(1-E_{j}^{r q}\right) /\left(m-\sum_{j=1}^{m} E_{j}^{r q}\right), \quad$ where $\quad 0 \leq W_{j}^{r q} \leq 1$, 
TABLE 4: Test evaluation indexes.

\begin{tabular}{|c|c|c|c|}
\hline Way & Evaluation index & Meaning & Type \\
\hline Eye tracker & $\begin{array}{c}\text { Fixation within AOI } \\
\text { Saccade time within AOI } \\
\text { Pupil area }\end{array}$ & $\begin{array}{c}\text { Extraction difficulty of early warning information } \\
\text { Information complexity of search process } \\
\text { Visual adaptation of driver }\end{array}$ & $\begin{array}{l}\text { Negative index } \\
\text { Negative index } \\
\text { Negative index }\end{array}$ \\
\hline EEG & $\begin{array}{l}\text { Power ratio } \alpha / \beta \\
\text { Power ratio } \theta / \alpha \\
\text { Power ratio } \theta / \beta \\
\end{array}$ & $\begin{array}{c}\text { Cognitive difficulty of driver } \\
\text { Subjective relaxation of driver } \\
\text { Degree of fatigue of driver }\end{array}$ & $\begin{array}{l}\text { Negative index } \\
\text { Negative index } \\
\text { Negative index }\end{array}$ \\
\hline Driving simulator & $\begin{array}{c}\text { Running time } \\
\text { Average speed } \\
\text { Maximum deceleration amount } \\
\text { Deceleration rate } \\
\text { Mean acceleration } \\
\text { Speed standard deviation } \\
\text { Lane changing times }\end{array}$ & $\begin{array}{l}\text { Driving efficiency of driver } \\
\text { Driving efficiency of driver } \\
\text { Operation stability of driver } \\
\text { Deceleration urgency of driver } \\
\text { Degree of psychological stress of driver } \\
\text { Degree of external effect on the driver } \\
\text { Lateral operation stability of driver }\end{array}$ & $\begin{array}{l}\text { Negative index } \\
\text { Positive index } \\
\text { Negative index } \\
\text { Negative index } \\
\text { Negative index } \\
\text { Negative index } \\
\text { Negative index }\end{array}$ \\
\hline
\end{tabular}

$\sum_{j=1}^{m} W_{j}^{r q}=1$. Finally, the index weight in various cooperative vehicle infrastructure scenes at various traffic levels is obtained. For example, for the long and steep downhill scene at high traffic level, it finds that $W^{18}$ is as follows: $(0.059$, $0.102,0.079,0.077,0.073,0.066,0.114,0.000,0.113,0.060$, $0.091,0.071,0.095)$.
Further, the weighted decision matrix is calculated as per the formula: $U^{r q}=W_{j}^{r q} * x_{i j}^{r q *}$. For example, for the long and steep downhill scene at high traffic level, it finds that $U^{18}$ is as follows:

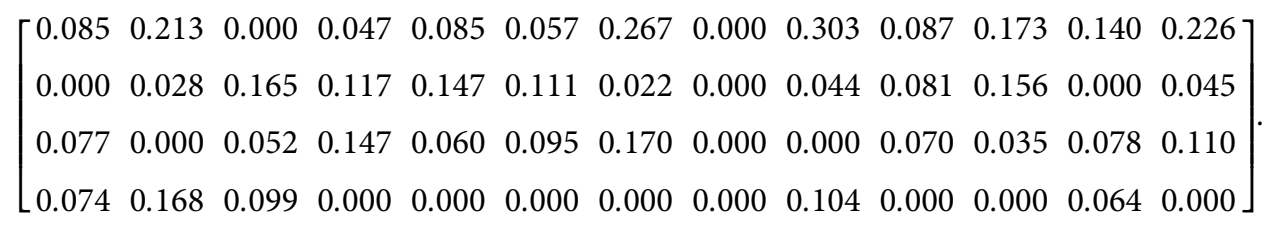

3.2.4. Comprehensive Evaluation by TOPSIS. First, determine the positive ideal solution $\left(U_{j}^{r q+}=\max \left\{U_{i j}^{r q}\right\}\right)$ and negative ideal solution $\left(U_{j}^{r q-}=\min \left\{U_{i j}^{r q}\right\}, j=1,2, \ldots, m\right)$ of each index. Next, calculate the Euclidean distance between each driving assistance scheme and positive ideal solution and negative ideal solution, namely, $D_{i}^{r q+}=\sqrt{\sum_{j=1}^{m}\left(u_{i j}^{r q}-U_{j}^{r q+}\right)^{2}}$ for positive ideal solution and $D_{i}^{r q-}=\sqrt{\sum_{j=1}^{m}\left(u_{i j}^{r q}-U_{j}^{r q-}\right)^{2}}$ for negative ideal solution. Finally, obtain the relative proximity $C_{i}^{r q}=D_{i}^{r q+} / D_{i}^{r q+}+D_{i}^{r q-}, 0 \leq C_{i}^{r q} \leq 1$ between each evaluation scheme and the optimal solution. The smaller $C_{i}^{r q}$ is, the better the scheme will be. For example, for the long and steep downhill scene at high traffic level, it finds that the results of the orthogonal test in the above different scenes are further subject to range analysis to obtain the best choice of form, timing, and frequency of each scene, as shown in Table 5.

\section{Discussion}

Unreasonable interactive information settings may decrease the safety and efficiency of vehicle driving. Therefore, determining the best information content, broadcasting form, timing, and frequency in different traffic scenarios is of great significance for driving.
This research is oriented to a series of intelligent highway scenarios, such as speed limit change, overspeed, sharp turns/continuous turns, long downhills, exit warning, service area warning, traffic jam warnings ahead, and warnings for stationary/slow vehicles ahead, and considers some of these scenarios have different effects on straight and curved road sections. Different types of human-machine interaction methods and driving assistance experiments considering orthogonal methods are designed. Then the NASA-LTX questionnaire, driving simulator, eye tracker, and EEG are used to evaluate the driver's feedback in different interaction modes and determine the optimal interaction mode of each cooperative vehicle infrastructure environment under high or low traffic flow from subjective and objective aspects, including the voice form, broadcast timing, and broadcast frequency.

The final conclusion is as follows:

(1) NASA-LTX questionnaire, driving simulator, eye tracker, and EEG are used to collect data and establish an index evaluation system. The form, trigger timing, and trigger frequency of human-machine interactive information are comprehensively evaluated from the subjective and objective aspects. It is found that the form of interactive information has the greatest effect on the driver, followed by the trigger timing and trigger frequency. 
TABle 5: Test results.

\begin{tabular}{|c|c|c|}
\hline Traffic level & Test scene & Optimal form \\
\hline High traffic & $\begin{array}{l}\text { Static/slow vehicle warning ahead at the straight line } \\
\text { Speed limit change at the straight line } \\
\text { Overspeed at the straight line } \\
\text { Sharp turn/continuous turn } \\
\text { Speed limit change at the curve } \\
\text { Static/slow vehicle warning ahead at the curve } \\
\text { Service area ahead } \\
\text { Long and steep downhill } \\
\text { Traffic congestion ahead } \\
\text { Exit ahead } \\
\text { Overspeed at the curve }\end{array}$ & $\begin{array}{l}\text { Short distance/low frequency/beep } \\
\text { Short distance/low frequency/beep } \\
\text { Short distance/low frequency/beep } \\
\text { Long distance/low frequency/voice } \\
\text { Short distance/low frequency/beep } \\
\text { Long distance/high frequency/beep } \\
\text { Short distance/low frequency/voice } \\
\text { Short distance/low frequency/beep } \\
\text { Short distance/low frequency/voice } \\
\text { Short distance/low frequency/voice } \\
\text { Long distance/high frequency/beep }\end{array}$ \\
\hline Low traffic & $\begin{array}{c}\text { Static/slow vehicle warning ahead at the straight line } \\
\text { Speed limit change at the straight line } \\
\text { Overspeed at the straight line } \\
\text { Sharp turn/continuous turn } \\
\text { Speed limit change at the curve } \\
\text { Static/slow vehicle warning ahead at the curve } \\
\text { Service area ahead } \\
\text { Long and steep downhill } \\
\text { Traffic congestion ahead } \\
\text { Exit ahead } \\
\text { Overspeed at the curve }\end{array}$ & $\begin{array}{l}\text { Long distance/high frequency/voice } \\
\text { Short distance/high frequency/beep } \\
\text { Long distance/low frequency/beep } \\
\text { Long distance/high frequency/voice } \\
\text { Long distance/low frequency/beep } \\
\text { Long distance/high frequency/voice } \\
\text { Short distance/low frequency/voice } \\
\text { Long distance/high frequency/beep } \\
\text { Long distance/low frequency/voice } \\
\text { Long distance/high frequency/voice } \\
\text { Long distance/high frequency/beep }\end{array}$ \\
\hline
\end{tabular}

(2) For different types of intelligent highway scenes, drivers have different tendencies in the selection of information form, trigger timing, and trigger frequency. For various assistance scenes at curves, the long-distance early warning timing and high early warning frequency provide better effects; for the exit-tip assistance scenes, the voice form is preferred; and for various speed assistance scenes, the beep form is better.

(3) In the design of human-machine interactive information in intelligent highway scenes, the effect of traffic level shall be considered. It is found that, at the high traffic level, short-distance early warning timing is preferred generally for various scenes while at the low traffic level, long-distance early warning timing is preferred.

This paper is of great significance to promote the rapid development of intelligent highway and the science of the information presented by vehicle driving assistance system. In future studies, the attributes of different drivers will be combined to make a more in-depth evaluation of different driving assistance means in various scenarios. In addition, different degrees of interference will be considered into the simulation through hardware-in-the-loop technology to test more safety interaction and preference.

\section{Data Availability}

The experiment data used to support the findings of this study have not been made available because of participants privacy and commercial confidentiality.

\section{Conflicts of Interest}

The authors declare that they have no conflicts of interest.

\section{Acknowledgments}

This research was supported by Projects of Zhejiang Transportation Department (2020006), Projects of Zhejiang Provincial Department of Science and Technology (2020C01057), the National Key Research and Development Program of China (2018YFB1601000), National Natural Science Foundation of China (52131204), and Shanghai Science and Technology Innovation Action Plan Project (19DZ1209004).

\section{References}

[1] J. Creaser and M. Manser, "Evaluation of driver performance and distraction during use of in-vehicle signing information," Transportation Research Record: Journal of the Transportation Research Board, vol. 2365, no. 1, pp. 1-9, 2013.

[2] E. E. Wiese and J. D. Lee, "Auditory alerts for in-vehicle information systems: the effects of temporal conflict and sound parameters on driver attitudes and performance," Ergonomics, vol. 47, no. 9, pp. 965-986, 2004.

[3] C. P. Fung, S. H. Chang, and C. C. Hsu, "The study on the influence of audio warning systems on driving performance using a driving simulator," in Proceedings of the 20th International Technical Conference on the Enhanced Safety of Vehicles, pp. 1-5, Lyon, France, June 2007.

[4] S. Winkler, J. Werneke, and M. Vollrath, "Timing of early warning stages in a multi stage collision warning system: drivers' evaluation depending on situational influences," Transportation Research Part F: Traffic Psychology and Behaviour, vol. 36, pp. 57-68, 2016.

[5] A. Doshi, S. Y. Cheng, and M. M. Trivedi, "A novel active heads-up display for driver assistance," IEEE Transactions on Systems, Man, and Cybernetics. Part B, Cybernetics: A Publication of the IEEE Systems, Man, and Cybernetics Society, vol. 39, pp. 85-93, 2009. 
[6] T. Wakasugi, "A study on warning timing for lane change decision aid systems based on driver's lane change maneuver," in Proceedings of the 19th International Technical Conference on the Enhanced Safety of Vehicles (ESV), Washington DC, USA, June 2005.

[7] X. Yan, Y. Zhang, and L. Ma, "The influence of in-vehicle speech warning timing on drivers' collision avoidance performance at signalized intersections," Transportation Research Part C: Emerging Technologies, vol. 51, pp. 231-242, 2015.

[8] C. Guo, C. Sentouh, J.-C. Popieul et al., "Cooperation between driver and automated driving system: implementation and evaluation," Transportation Research Part F: Traffic Psychology and Behaviour, vol. 61, pp. 314-325, 2019.

[9] S. Josephson and M. Myers, "Augmented reality through the lens of eye tracking," Visual Communication Quarterly, vol. 26, no. 4, pp. 208-222, 2019.

[10] J. Katona, T. Ujbanyi, G. Sziladi, and A. Kovari, "Speed control of Festo Robotino mobile robot using NeuroSky MindWave EEG headset based brain-computer interface," in Proceedings of the 7th IEEE international conference on cognitive infocommunications (CogInfoCom), pp. 251-256, IEEE, Wroclaw, Poland, October 2016.

[11] E. Galy, J. Paxion, and C. Berthelon, "Measuring mental workload with the NASA-TLX needs to examine each dimension rather than relying on the global score: an example with driving," Ergonomics, vol. 61, no. 4, pp. 517-527, 2018.

[12] X. Lu, M. Liu, and Y. Song, "Study on selection of logistic enterprise based on entropy-TOPSIS method," Railway Transport and Economy, vol. 36, no. 8, pp. 15-18, 2014. 